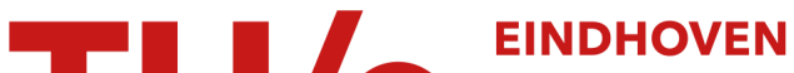 \\ UNIVERSITY OF \\ TECHNOLOGY
}

\section{Collaborative replenishment in the presence of intermediaries}

Citation for published version (APA):

Hezarkhani, B., Slikker, M., \& van Woensel, T. (2018). Collaborative replenishment in the presence of intermediaries. European Journal of Operational Research, 266(1), 135-146.

https://doi.org/10.1016/j.ejor.2017.09.033

\section{Document license:}

TAVERNE

DOI:

10.1016/j.ejor.2017.09.033

Document status and date:

Published: 01/04/2018

\section{Document Version:}

Publisher's PDF, also known as Version of Record (includes final page, issue and volume numbers)

\section{Please check the document version of this publication:}

- A submitted manuscript is the version of the article upon submission and before peer-review. There can be important differences between the submitted version and the official published version of record. People interested in the research are advised to contact the author for the final version of the publication, or visit the $\mathrm{DOI}$ to the publisher's website.

- The final author version and the galley proof are versions of the publication after peer review.

- The final published version features the final layout of the paper including the volume, issue and page numbers.

Link to publication

\section{General rights}

Copyright and moral rights for the publications made accessible in the public portal are retained by the authors and/or other copyright owners and it is a condition of accessing publications that users recognise and abide by the legal requirements associated with these rights.

- Users may download and print one copy of any publication from the public portal for the purpose of private study or research.

- You may not further distribute the material or use it for any profit-making activity or commercial gain

- You may freely distribute the URL identifying the publication in the public portal.

If the publication is distributed under the terms of Article $25 f a$ of the Dutch Copyright Act, indicated by the "Taverne" license above, please follow below link for the End User Agreement:

www.tue.nl/taverne

Take down policy

If you believe that this document breaches copyright please contact us at:

openaccess@tue.nl

providing details and we will investigate your claim. 


\title{
Collaborative replenishment in the presence of intermediaries
}

\author{
Behzad Hezarkhani ${ }^{\mathrm{a}, *}$, Marco Slikker $^{\mathrm{b}}$, Tom Van Woensel $^{\mathrm{b}}$ \\ a Nottingham University Business School, University of Nottingham, Jubilee Campus, Nottingham, NG8 1BB, UK \\ ${ }^{\mathrm{b}}$ School of Industrial Engineering, Eindhoven University of Technology, P.O. Box 513, Eindhoven 5600 MB, The Netherlands
}

\section{A R T I C L E I N F O}

Article history:

Received 19 December 2016

Accepted 18 September 2017

Available online 10 October 2017

\section{Keywords:}

Supply chain management

Procurement

Game theory

\begin{abstract}
A B S T R A C T
In complex supply chains, downstream buyers would often replenish individually from intermediaries instead of directly dealing with original manufacturers. Although collaborative replenishment from intermediaries might generate benefits, significant cost reductions could be achieved when direct replenishments from manufacturers are considered. This paper constructs a general model to study collaborative replenishment in multi-product chains with alternative sources of supply-i.e., manufacturers and intermediaries. A collaborative organization determines the optimal choices of replenishment sources on behalf of its members to minimize collective costs. We introduce a class of cooperative games associated with these situations and give sufficient conditions for their concavity. We investigate the choice of allocation rule and its effect on supply chain efficiency when buyers strategically participate in the collaborative organization. We prove that the Shapley value coordinates the supply chain, i.e., it makes complete participation the best strategy for buyers even under asymmetric information. This setting is compared with an alternative structure where buyers can only collaborate in source-specific replenishment organizations that purchase all requested products either from intermediaries or manufacturers. Although there are always participation strategies that result in minimum collective cost, it is impossible to find allocation rules for source-specific replenishment organizations that always motivate the buyers to choose such strategies.
\end{abstract}

(c) 2017 Elsevier B.V. All rights reserved.

\section{Introduction}

Intermediaries are economic entities who arbitrate transactions in between upstream suppliers and downstream buyers ( $\mathrm{Wu}$, 2004). According to the intermediation theory of the firm (Spulber, 1996), a firm is created when the gains from intermediated exchange exceed the gains from direct exchange. The gains created by intermediaries in many supply chains stem from aggregating demands of competing downstream buyers to achieve economy of scale, and consolidating upstream supply to reduce order and delivery costs. Traditionally, supply chain intermediaries generate these benefits via procuring products, holding inventories, and reselling them at a margin. Such activities add to the total cost of supply chains. This paper investigates the possibilities of increasing supply chain efficiency by reducing intermediation costs and excessive inventories-an objective that is attainable by collaboration among downstream buyers.

The enduring presence of intermediaries in certain supply chains implies that individual downstream buyers find it worth-

\footnotetext{
* Corresponding author.

E-mail address: behzad.hezarkhani@nottingham.ac.uk (B. Hezarkhani).
}

while to replenish indirectly even though intermediaries charge considerably higher prices than manufacturers. Despite price disparity, replenishing from local intermediaries often provides the opportunity to bundle orders for several products and receive them in one delivery, instead of dealing with numerous manufacturers whose minimum volume requirements, fixed ordering costs, or farther geographical distance impose higher replenishment costs and/or longer lead-times. By creating a critical mass, a collaborative organization of downstream buyers can take advantage of both direct and indirect replenishment sources to reduce total costs by choosing among the feasible replenishment policies for the organization's members. This paper constructs a general model to study collaborative replenishment in multi-product chains with alternative sources of supply-i.e., manufacturers and intermediaries. To the best of our knowledge, this paper is the first to consider collaborative organizations that could take advantage of such mixed policies.

The role of supply chain intermediaries are more significant in industries with high degree of product variability, market fragmentation, and sourcing globalization, e.g., in fashion, agro-food, and healthcare sectors as studied in Purvis, Naim, and Towill (2013), Appel, Franz, and Hassler (2014), and Moss (2012), respectively. This paper is particularly motivated by supply chain intermediation 
in the automotive after-sale market. The automotive after-market deals with thousands of products, comprises many echelons-e.g., manufacturers, importers, wholesalers, garages, and car ownersand is filled with excessive inventories and inefficiencies at various echelons (AASA, 2012). Collaborative purchasing and replenishment in this context is becoming an emerging trend to reduce costs and improve efficiency (London Economics, 2006). To materialize the joint replenishment initiatives and coordinate the decisions of downstream buyers, however, collaborative organizations are needed. Such collaborative organizations would serve as hubs for gathering relevant information from the members, taking and executing purchasing decisions, managing payments, and sharing costs. The latter can be managed by an independent firm. In our motivating case in automotive after-market, the company IZImotive (http://www.izimotive.nl/) coordinates the replenishments of delegated products for downstream buyers. Supported by Dutch Institute for Advanced Logistics (DINALOG), IZI-motive is created as a platform to facilitate collaboration among buyers of automotive parts in order to reduce the inefficiencies resulting from the presence of intermediaries in the supply chain. Having negotiated volume discounts and arranged logistics infra-structure, IZI-motive enables buyers to jointly replenish directly from manufacturers in volumes that make it less costly than individual purchases from the intermediaries. Not only this practice reduces the purchasing costs of the parts, but also it drastically limits the number of delivery trips of the parts to the buyers (DINALOG, 2017). IZI-motive only deals with purchases from the manufacturers since collaborative replenishments from the local intermediaries does not generate substantial savings.

In this paper, we formalize Collaborative Replenishment in the presence of Intermediaries as a CRI situation. CRI situations present a general modeling framework for joint replenishment of multiple products by several buyers with the option of sourcing each product directly or indirectly from manufacturers or intermediaries. The downstream buyers sell to the market. The manufacturers produce distinctive products. Meanwhile, intermediaries procure products from the manufacturers and supply to the downstream buyers at higher unit prices. Note that although intermediaries and manufacturers constitute alternative sources of supply, they exhibit some contrasting features.

The potential savings are also obtained from consolidating orders (of different products or different buyers) from the same source. This is because average replenishment costs of a product could decrease if buyers (a) individually replenish more products from intermediaries (and/or manufacturers), and (b) jointly replenish from manufacturers (and/or intermediaries) in larger groups. These conditions reflect the incentives for collaboration and the possible conflict between the economies of scale in dealing with direct and indirect replenishment sources. Fig. 1 depicts an example of a CRI situation with three buyers requiring three different products. The replenishment policy chosen by the collaborative organization in this example dictates that buyer 1 replenishes products $c$ and $b$ from the intermediary jointly with buyers 2 and 3 who also replenish product $c$ from intermediary, and product $a$ from its manufacturer jointly with buyers 2 and 3 who also replenish product $a$ and $b$ directly.

The CRI situations in this paper combine source-specific replenishment cost functions, i.e., cost components, that obtain minimum costs of replenishing different sets of product-player pairs from manufacturers or intermediaries. Depending on the conditions imposed on such cost components, the results in this paper are of three types. The first type of results pertains to general CRI situations with non-decreasing and subadditive cost componentsthe most basic conditions that justifies collaborative replenishment. The second type of results is specific to the class of submodular CRI situations, i.e., situations whose cost components are

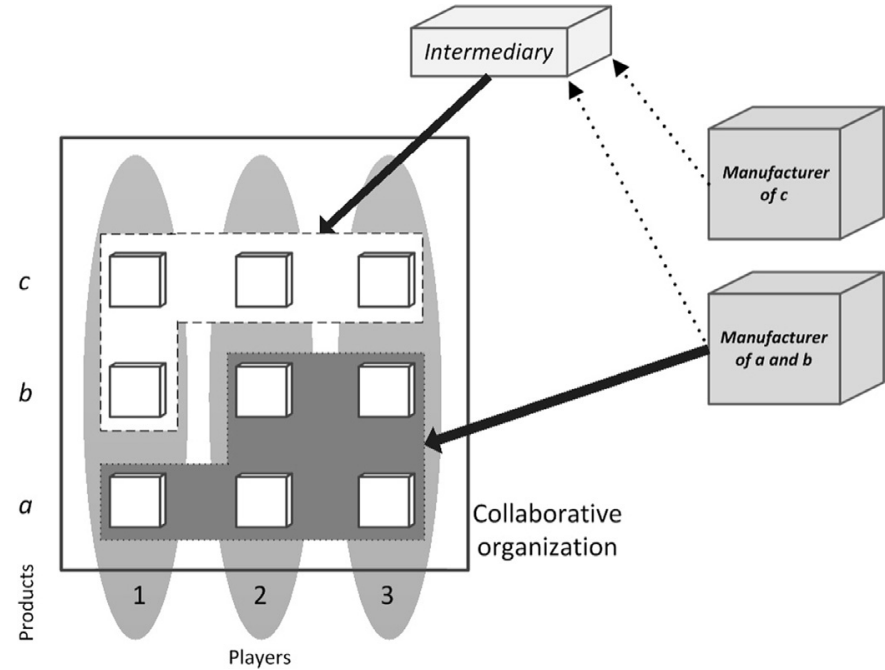

Fig. 1. Graphical representation of a replenishment policy in collaborative organization.

submodular. The class of submodular CRI situations builds upon important joint replenishment models in the literature including, but not limited to Meca, Timmer, Garcia-Jurado, and Borm (2004), Anily and Haviv (2007), Zhang (2009), Heuvel, Borm, and Hamers (2007), Hartman, Dror, and Shaked (2000), and Özen, Norde, and Slikker (2011) among others. Therefore, the second type of results presented in this paper holds for multi-product-multi-source extensions of aforementioned models. The third type of results addresses submodular CRI situations with separable indirect replenishment costs, that is, situations wherein collaborative replenishments by groups of buyers from intermediaries do not provide additional cost savings-although for individual buyers joint replenishments of multiple products from the intermediaries can still be beneficial. Such situations are motivated by our observation in automotive after-market where collaborative purchases from local intermediaries lack significant benefits.

The starting point in our study is to elaborate on the underlying optimization problem in CRI situations and to study optimal replenishment policies. Generally, obtaining the optimal replenishment policies requires solving a combinatorial optimization problem. For submodular CRI situations, however, we show that total cost functions are submodular and consequently the optimal replenishment policies can be found using a strongly polynomial algorithm. Adding the separable indirect replenishment costs assumption, we show that the optimal replenishments from manufacturers exhibit a nested property meaning that if it is optimal for a group of buyers to replenish a product directly from its manufacturer, doing so by those buyers remains optimal in every group containing the former buyers. Therefore, direct replenishers of a product never grow smaller as more buyers join the collaborative organization. The objectives and contributions of this paper are three fold:

1. To understand the nature of collaboration among the buyers, we construct the class of cooperative CRI games and analyze their properties. Cooperative CRI games on the whole are subadditive which attests to the benefits of collaborative replenishments. However, it can be challenging to devise an allocation rule for sharing the costs among the players in ways that support the stability of collaborative organizations. We examine conditions that result in concavity of cooperative CRI games. Concave games are appealing inasmuch as the Shapley value (Shapley, 1953) always constitutes an allocation rule that (a) is within the core (Gillies, 1959) so that subgroup of players do not have the incentive to 
break apart, and (b) is population monotonic (Sprumont, 1990) so that joining of new members would never have a negative effect on the allocated gains of existing members. Somewhat counterintuitively, games associated with submodular CRI situations can be non-concave, even though their total cost functions are always submodular. Nevertheless, we prove that under the separability assumption on indirect replenishment costs, games associated with submodular CRI situations are concave.

2. We allow downstream buyers to strategically decide about the extent of their participation in collaborative organizations and introduce the class of two-stage CRI games. In the first stage the buyers choose the products they wish to replenish via the collaborative organization. In the second stage the withheld products would be replenished individually while the cooperative CRI game induced by the participation strategies of the buyers in stage one is played and the joint costs will be divided according to a known allocation rule. In two-stage CRI games the grand coalition benefits the most if all buyers participate with all of their products so that the collaborative organization can take the centrally optimal replenishment policies. But individual buyers may choose other strategies if they perceive that partial participation would be to their interest. For general CRI situations, we show that with the Shapley value as the allocation rule for sharing the joint costs, individual buyers can never make a better move than adopting the complete participation strategies irrespective of others' strategies, that is, the complete participation strategy profile is always weakly dominant. In this sense the Shapley value implements the centrally optimal replenishment policies in dominant strategies. Maskin and Sjöström (2002) explain that this is the most demanding form of implementation which is often impossible to achieve. Moreover, with the Shapley value complete participation is the only weakly dominant strategy profile when the buyers have asymmetric information about the situation. We conclude that the Shapley value has the ability to coordinate the supply chain in CRI situations.

3. We investigate the possibility of achieving supply chain coordination in an alternative setting with source-specific replenishment organizations that instead of making decisions on the sources of products, purchase every requested product either from the intermediaries or the manufacturers. The rationale is that it can be easier to set up and maintain collaborative organizations that do not make strategic sourcing decisions on behalf of their members. We answer the following question: is it possible to choose allocation rules that motive the buyers to participate in sourcespecific replenishment organizations in such a way that centrally optimal policies are always implemented? The answer to the latter question shed light on shortcomings of the approach which combines existing single-source joint replenishment models to deal with multi-source situations. We demonstrate that irrespective of the choice of allocation rules, strategic participation of buyers in source-specific replenishment organizations can make optimal supply chain performance impossible to achieve-even if joint replenishments from intermediaries are not beneficial. The intuition derived from this result for our motivating case is that the collaborative organization must take responsibility for making decisions regarding the replenishment sources of requested products if supply chain coordination is sought after.

The rest of this paper is organized as follows. In Section 2, we briefly overview the relevant literature. Section 3 contains an overview of main concepts used in this paper. In Section 4 we formally introduce the CRI situations and examine their properties. The cooperative cost games associated with CRI situations are studied in Section 5 where the corresponding cost-sharing problem is also addressed. The two-stage CRI games are investigated in Section 6. Section 7 discusses the alternative structure with sourcespecific replenishment organizations where all the requested prod- ucts of the players are replenished via intermediaries or manufacturers. Section 8 concludes the paper.

\section{Literature review}

Several papers in the literature elaborate on the opportunities for consolidating costs, obtaining lower purchase prices, carrying less stocks, and reducing risks of supply/demand uncertainty as the result of collaboration in replenishment and procurement activities. Dror and Hartman (2011) and Fiestras-Janeiro, GarcíaJurado, Meca, and Mosquera (2011) provide surveys of cooperative and non-cooperative games associated with replenishment and procurement situations.

An important advantage in collaborative replenishment is the possibility of aggregating order and/or delivery costs. Drawing upon basic EOQ model, Meca et al. (2004) introduce the class of inventory games where downstream players aggregate their logistics costs by placing joint orders and show that the total cost is submodular on the set of players. Dror and Hartman (2007) extend the basic inventory game to the setting which takes into account the player-specific order costs in the joint replenishment process. They show that collaborative replenishment may not necessarily be beneficial if players could only place joint orders simultaneously. However, Anily and Haviv (2007) prove that if replenishment policies follow the powers-of-two (Jackson, Maxwell, \& Muckstadt, 1985) structure, so that downstream players are not forced to synchronize all of their orders, the collaborative replenishment is always beneficial and the total cost is submodular on the set of players. Zhang (2009) extends this result to situations where players are allowed to have a joint inventory stocking point and obtains similar results. Heuvel et al. (2007) introduce and investigate the class of economic lot-sizing games wherein players face periodic, yet deterministic, demand and have the option to place joint orders. They introduce cases in which the joint cost function is submodular. In situations closely related to lot-sizing games, Guardiola, Meca, and Puerto (2008) and Guardiola, Meca, and Puerto (2009) introduce and investigate production-inventory games as another class of totally balanced combinatorial optimization games and estate conditions for the concavity of these games that result in submodularity of the joint cost functions. Timmer, Chessa, and Boucherie (2013) extend the model in Meca et al. (2004) to Poisson demand and conjecture the submodularity of the corresponding cost function. In a related study that generalizes some models of cooperative inventory management and group purchasing, Meca and Sošić (2014) examine the role of different types of players in terms of the benefits that they provide for or obtain from collaborative interactions and their effect on the stability of the associated games. Meca and Sošić (2016) extend the latter games and introduce the supremum-norm cost games as yet another class of totally balanced cooperative games.

The collaborative replenishment problem has also been investigated in settings with strategic players. Meca, García-Jurado, and Borm (2003) study a single-item inventory game in strategic form with players announcing their desired replenishment cycles to an intermediary who places orders with the manufacturer. Alternative games with players announcing their contribution to ordering costs are investigated by Körpeoğlu, Şen, and Güler (2012) and Körpeoğlu, Şen, and Güler (2013). The latter models allow players to be privately informed about their types. Finally, Bylka (2011) analyze an inventory batching game in strategic form and describe the structure of Nash equilibria.

In addition to consolidating fixed costs, collaborative replenishment can also reduce the risks associated with stochastic demands. The extensive line of research on risk pooling in inventory management and procurement starts with the work of Hartman et al. (2000) and in the context of newsvendor problems. Slikker, Fran- 
soo, and Wouters (2005) further study these situations while allowing downstream players to transship unused products amongst themselves and show that allocations in the core always exists. Özen et al. (2011) particularly study situations where the corresponding collaborative replenishment models have submodular cost functions. Montrucchio, Norde, Özen, Scarsini, and Slikker (2012) provide a review of cooperative newsvendor games. Infinitehorizon versions of inventory risk pooling games are studied in Karsten, Slikker, and van Houtum (2012) and Karsten and Basten (2014) in the context of expensive and low-demand spare parts.

Another stream of research focuses on the cost-sharing problems in collaborative purchasing organizations that take advantage of suppliers' discount schedules. Nagarajan, Sošic, and Zhang (2010) compare some of the well-known allocations for dividing the joint costs in such situations. Schotanus, Telgen, and de Boer (2008) discuss the unfairness of the equal price allocation method in purchasing groups. Schaarsberg, Borm, Hamers, and Reijnierse (2013) introduce and analyze the class of maximum collaborative purchasing situations and their associated games where the purchase price of a group of players is determined by the largest order quantity of the players in the group. In the context of health-care supply chains, the effect of group purchasing organizations on distribution of profit and providers' total purchasing cost have been investigated in Hu, Schwarz, and Uhan (2012).

A number of papers in the operations management literature investigate multi-stage games that mixes non-cooperative and cooperative games intertwined in sequential stages. Brandenburger and Stuart (2007) provide an axiomatic approach to two-stage games which they refer to as biform games. Stuart (2005) use the biform game structure to investigate the pricing decisions following the inventory decisions among a group of competing newsvendors. In the context of inventory pooling and transshipments, Anupindi, Bassok, and Zemel (2001) study the choice of allocation rules for the cooperative game in second stage and its effect on the first stage strategies. They show that the use of dual allocations (Owen, 1975) makes the centrally optimal order quantities a Nash equilibrium (Nash, 1950) in the first stage non-cooperative game. However, Granot and Sošić (2003) show that if the players have the option to choose the extent of their participation in the transshipment stage, in terms of the level of inventories they share, partial participation may be more beneficial than complete participation. As they prove, the use of Shapley value as the allocation rule provides sufficient incentives for the players to participate completely but then it cannot guarantee that the grand coalition is formed by the players. Nevertheless, Yan and Zhao (2015) show that complete participation as well as the formation of grand coalition can be achieved if collaboration is managed by an external entity who subsidizes the system. Including the supplier into the model analyzed by Anupindi et al. (2001), Kemahlioglu-Ziya and Bartholdi (2011) establish that with the Shapley value as the allocation rule, the retailers have incentive to join the inventory pooling coalition and the supplier carries the level of inventory that is optimal for the coalition. Özen, Fransoo, Norde, and Slikker (2008) study a two-stage inventory pooling game with warehouses and show that the set of pay-off vectors resulting from strong Nash equilibria corresponds to the core of the cooperative game played in the second stage.

\section{Preliminaries}

Set functions. Given a finite set $\Omega$, and its power set $\varepsilon_{0}(\Omega), f$ : $\wp(\Omega) \rightarrow \mathbb{R}$ is a set function that gives real values to subsets of $\Omega$. The following properties of set functions are of interest:

- $f$ is non-decreasing if for every $A \subset B \subseteq \Omega$ we have $f(A) \leq f(B)$.
- $f$ is subadditive if for every $A, B \subset \Omega, A \cap B=\emptyset$, we have $f(A \cup$ $B) \leq f(A)+f(B)$.

- $f$ is submodular if for every $A \subseteq B \subset \Omega$ and every element $a \in \Omega \backslash B$ it holds that $f(B \cup a)-f(B) \leq f(A \cup a)-f(A){ }^{1}$

The returned value of a non-decreasing set function never decreases as the result of including more elements. Subadditivity limits the amount of increase due to including more elements so that the value of union of two disjoint sets does not exceed their sum. A submodular set function demonstrates a diminishing returns property which makes it analogous to concave continuous functions.

Cooperative games. A Transferable Utility (TU) cooperative cost game is a pair $(N, c)$ where $N$ is a finite set of players and $c$ : $\wp(N) \rightarrow \mathbb{R}$ a set function with $c(\emptyset)=0$ that determines the cost to be paid by each group of players. The game $(N, c)$ is subadditive if $c$ is subadditive on the set of players and it is concave if $c$ is submodular on the set of players. An allocation for players in $N$ is $\beta=\left(\beta_{i}\right)_{i \in N}$ such that $\beta_{i} \in \mathbb{R}$ for every $i \in N$. An allocation $\beta$ is efficient for $(N, c)$ if $\sum_{i \in N} \beta_{i}=c(N)$. An allocation $\beta$ is individually rational for $(N, c)$ if $\beta_{i} \leq c(\{i\})$ for all $i \in N$. An allocation rule is stable for $(N, c)$ if for any $S \subseteq N$ it holds that $\Sigma_{i \in S} \beta_{i} \leq c(S)$. The core of a game contains all of its efficient and stable allocations.

Non-cooperative games. A cost game in strategic form is a triple $(N$, $A, z)$ where $N$ denotes the set of players, $A=\left(A_{i}\right)_{i \in N}$ is the vector of strategy sets of players and $z=\left(z_{i}\right)_{i \in N}$ is the vector of playerspecific cost functions which assign values to every strategy profile $L=\left(L_{i}\right)_{i \in N}$ with $L_{i} \in A_{i}$ for every $i \in N$. For $S \subseteq N$, let $L_{S}$ be the reduction of $L$ to players in $S$ and let $L_{-S}$ be the reduction of $L$ to players in $N \backslash S$. The following strategy profiles are of interest in this paper:

- $L$ is a Nash equilibrium if for every $i \in N$ and every $L_{i}^{\prime} \in A_{i}$ it holds that $z_{i}(L) \leq z_{i}\left(L_{i}^{\prime}, L_{-i}\right)$.

- $L$ is a weakly dominant strategy profile if for every $i \in N$ and every $L^{\prime} \in \prod_{i \in N} A_{i}$ it holds that $z_{i}\left(L_{i}, L_{-i}^{\prime}\right) \leq z_{i}\left(L^{\prime}\right)$.

Unilateral deviations from a Nash equilibrium does not reduce the cost of any players. A weakly dominant strategy for a player is its best choice of strategy irrespective of other players' choices. The last concept is a refinement of Nash equilibrium meaning that if $L$ is a weakly dominant strategy profile, it is also a Nash equilibrium. The reverse does not hold necessarily.

\section{CRI situations}

Consider a supply chain with a set of downstream buyers, hereafter the players, represented by the index set $N=\{1, \ldots, n\}$, replenishing a variety of different products to sell in their local markets. The set of products replenished by a player $i \in N$ is denoted by $E_{i}$. The vector $E=\left(E_{i}\right)_{i \in N}$ denotes the player-specific product sets. Products are produced and sold by a set of manufacturers. In addition to the manufacturers, supply chain intermediaries, e.g., regional wholesalers or volume distributors, also sell some or all products. The players have the option to obtain each product either from its corresponding manufacturer or from the intermediaries. A CRI situation is the tuple $\Gamma=\left(N, E, r_{w}, r_{m}\right)$ with $r_{w}$ and $r_{m}$ being the indirect and direct cost components which will be discussed in detail below. The set of all CRI situations with player set $N$ is denoted by $\boldsymbol{\Gamma}$.

Replenishment polices, which represent the various choices regarding the replenishment sources of different products for different players, are the main decision variables in CRI situations. We

\footnotetext{
${ }^{1}$ For notational convenience we do not use braces for union and exclusion of single element sets. That is, we write $A \cup a$ instead of $A \cup\{a\}$ and $A \backslash a$ instead of $A \backslash\{a\}$.
} 
assume that the choices of replenishment sources of all products and all players are binary, i.e., a product required by a player is sourced either from the intermediaries or its corresponding manufacturer. Thus, in order to completely describe the replenishment actions of all players with regard to all products, it is sufficient to underline the replenishments from one of the sources only. We define the replenishment choice set of a player $i, i \in N$, as the set of all player-product pairs specific to $i$ and denote it by $\mathcal{X}_{i}^{\Gamma}=\{(i, l) \mid l \in$ $\left.E_{i}\right\}$. The replenishment choice sets for groups of players are obtained accordingly by taking the union of their individual choice sets. For every $S \subseteq N$, we denote the replenishment choice set of $S$ by $\mathcal{X}_{S}^{\Gamma}=\bigcup_{i \in S} \mathcal{X}_{i}^{\Gamma}$. We define a replenishment policy, $X$, as a collection of player-product pairs that are replenished directly from the manufacturers. A replenishment policy $X$ is feasible for players in $S \subseteq N$ whenever $X \subseteq \mathcal{X}_{S}^{\Gamma}$. Note that with this definition a feasible replenishment policy for a subset of players is also feasible for other subsets of players which contain the former players. However, the reverse does not hold necessarily.

We differentiate between the two major cost components corresponding to the two sources of supply for products: indirect and direct replenishment costs. When a rational buyer, or a group of rational buyers jointly, replenishes a subset of products from a specific source, i.e. the intermediaries or the manufacturers, corresponding decision variables- such as batch sizes, ordering cycles, order bundles, etc.-would be chosen to attain the minimum possible per-period replenishment cost for that specific source. We refrain from the operational details at this level and instead introduce the indirect replenishment cost function $r_{w}: \wp\left(\mathcal{X}_{N}^{\Gamma}\right) \rightarrow \mathbb{R}$ and direct replenishment cost function $r_{m}: \wp\left(\mathcal{X}_{N}^{\Gamma}\right) \rightarrow \mathbb{R}$ that give the minimum per-period replenishment cost of different sets of playerproduct pairs from the intermediaries and the manufacturers respectively.

We assume that the indirect and direct replenishment cost functions are non-decreasing and subadditive on the replenishment choice sets. The first condition reflects the intuitive scenario where replenishing $k+1$ player-product pairs from the intermediaries or the manufacturers is never less costly that replenishing $k$ playerproduct pairs among the latter set from the same source. The second condition asserts that the sum of (in)direct replenishment costs of mutually exclusive player-product sets is never less costly than the (in)direct replenishment cost of their union. The last assumption follows immediately from the definition of $r_{w}$ and $r_{m}$. If the joint ordering of two disjoint player-product sets $X$ and $X^{\prime}$ from intermediaries or manufacturers involves more costs than the sum of their separate orderings from the same source, $r_{w}\left(X \cup X^{\prime}\right)$ or $r_{m}\left(X \cup X^{\prime}\right)$ by definition would give the sum of separate ordering costs instead of the cost of joint ordering. In the rest of the paper we let $r_{w}(\emptyset)=r_{m}(\emptyset)=0$.

An important special case in CRI situations, which is observed in our motivating case in automotive after-market, is when the indirect replenishment costs from intermediaries are additive over the set of players, that is, intermediaries cater to players on the individual bases and no additional savings can be obtained by combining the indirect replenishments of different players. We refer to this case with separable indirect replenishment cost.

Definition 1. $r_{w}$ is separable over the set of players if for every $T \subseteq N$ and an arbitrary $X \subseteq \mathcal{X}_{T}^{\Gamma}$ we have $r_{w}(X)=\sum_{i \in N} r_{w}\left(\mathcal{X}_{i}^{\Gamma} \cap X\right)$.

Given $S \subseteq N$, we define the replenishment cost function for $S, r_{S}^{\Gamma}$ : $\wp\left(\mathcal{X}_{S}^{\Gamma}\right) \rightarrow \mathbb{R}$, such that for every feasible replenishment policy for $S, X \subseteq \mathcal{X}_{S}^{\Gamma}$, we have

$r_{S}^{\Gamma}(X)=r_{m}(X)+r_{w}\left(\mathcal{X}_{S}^{\Gamma} \backslash X\right)$.

The cost of a replenishment policy $X$ for $S$ is the sum of direct replenishment cost of player-product sets in $X$ and the indirect replenishment costs of the remainder of player-products sets in the choice set of $S$. An optimal replenishment policy for a subset of players has the lowest replenishment cost among all feasible replenishment policies for those players. The cost of an optimal replenishment policy for $S \subseteq N$ is denoted by:

$c^{\Gamma}(S)=\min _{X \subseteq \mathcal{X}_{S}^{\Gamma}} r_{S}^{\Gamma}(X)$

\subsection{Submodular CRI situations}

We call a CRI situation submodular if its cost components are submodular on the replenishment choice sets. The following definition formalizes this.

Definition 2. A CRI situation $\Gamma=\left(N, E, r_{w}, r_{m}\right) \in \boldsymbol{\Gamma}$ is submodular if $r_{w}$ and $r_{m}$ are submodular on $\mathcal{X}_{N}^{\Gamma} . \Gamma^{s m} \subset \Gamma$ is the set of all submodular CRI situations.

The motivation for focusing on this class of CRI situations is that in the single-source joint replenishment literature, several cost functions are proven to have a submodular structure. These models include, but are not limited to, deterministic joint replenishment problems discussed in Meca et al. (2004), Anily and Haviv (2007), Zhang (2009), special cases in Heuvel et al. (2007), as well as stochastic models considered in Hartman et al. (2000) and Özen et al. (2011). Therefore, a CRI situation with cost components derived from the aforementioned single-source replenishment models is a specific instance of a submodular CRI situation.

Submodularity of a CRI situation has important consequences. The first result in this paper states that submodularity of the cost components is a sufficient condition for submodularity of total cost functions in CRI situations. All proofs are given in the supplement.

Lemma 1. Let $\Gamma \in \Gamma^{s m}$. For every $S \subseteq N, r_{S}^{\Gamma}$ is submodular on $\mathcal{X}_{S}^{\Gamma}$.

The submodularity of total cost in submodular CRI situations means that as the set of player-product pairs replenished from the manufacturers grows, the marginal cost of adding another playerproduct pair is non-increasing. Thus, replenishing from manufacturers can become more beneficial if more player-product pairs are included. This demonstrates the economy of scale in direct replenishments from the manufacturers. A similar argument can be stated in terms of player-product sets that are replenished via the intermediaries. As the result of submodularity of total cost, it can be verified that expanding the set of player-products that are replenished from the intermediaries has a non-increasing effect on the marginal costs of additional player-product sets that are replenished from the intermediaries. Thus, one can observe economies of scale in opposite directions in submodular CRI situations.

The submodularity of CRI situations also has important consequences with regard to the tractability of the optimization problem in (2). Grötschel, Lovász, and Schrijver (1988) show that for a submodular function, the Ellipsoid method can be used to construct a strongly polynomial algorithm for its minimization. Hence, submodularity of CRI situations implies that the optimal replenishment policies can be found efficiently. In the remainder of this section we elaborate on certain properties of optimal replenishment policies in submodular CRI situations.

Lemma 2. Let $\Gamma \in \Gamma^{s m}$. If alternative optimal replenishment policies exist for $S \subseteq N$, their union is also an optimal replenishment policy for $S$.

Lemma 2 states that the union of two optimal replenishment policies for a group of players is in itself another optimal replenishment policy. Thus, it can be inferred that for every group of players, there exists an optimal replenishment policy with the most number of player-product pairs replenished from the manufacturers. Similar line of reasoning can be used to show that in 
Table 1

Situation in Example 1.

\begin{tabular}{lll}
\hline$X$ & $r_{w}(X)$ & $r_{m}(X)$ \\
\hline$\{(1, a)\}$ & 20 & 15 \\
$\{(2, a)\}$ & 10 & 10 \\
$\{(3, a)\}$ & 10 & 10 \\
$\{(1, a),(2, a)\}$ & 25 & 25 \\
$\{(1, a),(3, a)\}$ & 25 & 25 \\
$\{(2, a),(3, a)\}$ & 20 & 20 \\
$\{(1, a),(2, a),(3, a)\}$ & 30 & 35 \\
\hline
\end{tabular}

Table 2

Optimal policies in Example 1.

\begin{tabular}{ll}
\hline$S$ & $X_{S}^{*}$ \\
\hline$\{1\}$ & $\{(1, a)\}$ (unique) \\
$\{2\}$ & $\{(2, a)\}$ \\
$\{3\}$ & $\{(3, a)\}$ \\
$\{1,2\}$ & $\{(2, a)\}$ \\
$\{1,3\}$ & $\{(3, a)\}$ \\
$\{2,3\}$ & $\{(2, a),(3, a)\}$ \\
$\{1,2,3\}$ & $\emptyset$ (unique) \\
\hline
\end{tabular}

these situations there also exists an optimal replenishment policy with the least number of player-product pairs replenished from the manufacturers.

When the indirect replenishment cost function is separable over the set of players, additional insights can be gained. In order to do so, we use the following relationship between the costs of a feasible replenishment policy for two subsets of players in situations with separable indirect replenishment costs.

Lemma 3. Let $\Gamma \in \boldsymbol{\Gamma}$ such that $r_{w}$ is separable over players, and consider $S \subset T \subseteq N$. Let $X$ be a feasible replenishment policy for $S$. We have $r_{T}^{\Gamma}(X)=r_{S}^{\Gamma}(X)+r_{w}\left(\mathcal{X}_{T \backslash S}^{\Gamma}\right)$.

Lemma 3 allows one to evaluate the cost of a replenishment policy $X$ that is feasible for $S \subset N$ for its supersets. To do so, indirect replenishment costs of the entire product sets of extra players must be added to the replenishment cost of $X$ for $S$. We are now ready to show a nested property in growing subsets of players in submodular situations with separable indirect replenishment costs.

Lemma 4. Let $\Gamma \in \Gamma^{s m}$ such that $r_{w}$ is separable over players. Let $X_{S}^{*}$ be an optimal replenishment policy for $S \subset N$. For every $T \subseteq N, T \supset S$, there exists an optimal replenishment policy $X_{T}^{*}$ such that $X_{T}^{*} \supseteq X_{S}^{*}$.

According to the last Lemma, if it is optimal for a subset of players to collectively replenish certain products from their manufacturers, it would also be optimal that this subset of players keep on doing the same in any other subset that contains the former players. The latter can be interpreted in an alternative way: in submodular CRI situations with separable indirect replenishment costs, the set of direct replenishers of a product never shrink as the result of including more players to the collaborative organization. A direct consequence of the nested property of optimal replenishment policies in Lemma 4 is that in submodular CRI situations the optimal policies for larger subsets of players can be built upon those of the smaller subsets. It must be noted that without the separability condition on indirect replenishment costs the nested property cannot be guaranteed. The following example illustrates this.

Example 1. Table 1 demonstrates the cost components in a CRI situation with three players and a single product. It can be easily verified that this is a submodular but not separable over players situation. From Table 2 we can see that for player 1, it is uniquely optimal to replenish the product from the manufacturer. However, in the grand coalition the unique optimal policy is to replenish jointly
Table 3

Situation in Example 2.

\begin{tabular}{lll}
\hline$X$ & $r_{w}(X)$ & $r_{m}(X)$ \\
\hline$\{(1, a)\}$ & 6 & 8 \\
$\{(2, a)\}$ & 6 & 8 \\
$\{(3, a)\}$ & 5 & 7 \\
$\{(1, a),(2, a)\}$ & 11 & 9 \\
$\{(1, a),(3, a)\}$ & 10 & 13 \\
$\{(2, a),(3, a)\}$ & 11 & 13 \\
$\{(1, a),(2, a),(3, a)\}$ & 15 & 14 \\
\hline
\end{tabular}

from the intermediaries. Thus, the nested property does not hold. $\triangle$

\section{Cooperative CRI games}

In this section we study the collaboration among players in CRI situations with the help of a class of cooperative cost games associated with these situations. The cooperative cost games associated with CRI situations, hereafter cooperative CRI games, can be constructed by considering the set of players $N$ and defining the characteristic function to be the optimal replenishment cost function. Thus, for every CRI situation $\Gamma \in \Gamma$, one can define an associated cooperative cost game by $\left(N, c^{\Gamma}\right)$ where for every $S \subseteq N, c^{\Gamma}(S)$ is defined as in Eq. (2). Note that by definitions of direct and indirect replenishment cost functions we have $c^{\Gamma}(\emptyset)=0$. The first result in this section exhibits the subadditivity of general CRI games.

Theorem 1. For every $\Gamma \in \Gamma$, the associated cooperative game $\left(N, c^{\Gamma}\right)$ is subadditive.

Subadditivity of CRI games implies that the optimal replenishment cost for the case where all players are participating in the collaborative organization is never higher than the sum of the costs of any other partitionings of the players into independent collaborative organizations. Thus, subadditivity of CRI games incentivizes the formation of the grand coalition as the participation of all players in the game guarantees the minimum collective costs. However, incentives for individual players stemming from their allocated costs still need to be addressed. In what follows we discuss the possibilities for having appropriate cost allocations in the grand coalition.

\subsection{Concavity of CRI games}

In a concave game the contributions of players to the cost of growing subsets of players are non-increasing. The concavity of a cooperative game has important implications with regard to ease of finding appropriate allocation rules which will be discussed in the next section. Remember that for a submodular CRI situation, its cost components are submodular on the replenishment choice set while concavity of the associated game requires that the optimal replenishment cost function be submodular on the set of players. It is essential to understand that submodular CRI situations are not necessarily associated with concave games. The following example demonstrates this.

Example 2. Consider a CRI situation with three players and a single product. The cost components are depicted in Table 3. It can be verified that both $r_{w}$ and $r_{m}$ are submodular on the replenishment choice set. The cooperative game associated with this situation is described in Table 4. We have:

$$
\begin{aligned}
c^{\Gamma}(\{1,3\})-c^{\Gamma}(\{1\})= & 10-6=4, \quad \text { and } c^{\Gamma}(\{1,2,3\}) \\
& -c^{\Gamma}(\{1,2\})=14-9=5 .
\end{aligned}
$$


Table 4

Game in Example 2.

\begin{tabular}{ll}
\hline$S$ & $c^{\Gamma}(S)$ \\
\hline$\{1\}$ & 6 \\
$\{2\}$ & 6 \\
$\{3\}$ & 5 \\
$\{1,2\}$ & 9 \\
$\{1,3\}$ & 10 \\
$\{2,3\}$ & 11 \\
$\{1,2,3\}$ & 14 \\
\hline
\end{tabular}

The inclusion of player 3 to player 1 adds less cost than inclusion of player 3 to coalition $\{1,2\}$. Therefore the game is not concave, even though the situation is submodular. $\triangle$

Example 2 shows that submodularity of total replenishment cost for all subsets of players on the set of replenishment choices does not automatically imply submodularity of the associated games on the set of players. However, when the indirect replenishment costs are separable, then the games associated with submodular CRI situations are in fact concave.

Theorem 2. For every $\Gamma \in \Gamma^{s m}$ with separable indirect replenishment costs, the associated cooperative game $\left(N, C^{\Gamma}\right)$ is concave.

\subsection{Allocation rules}

An important question in every cooperative situation concerns the division of joint costs among the participants. There are certain properties that a desirable allocation must satisfy. One of the most basic desirable properties of an allocation is the efficiency property which requires that the total cost of the set of all players (grand coalition) is entirely divided among the players. Another desirable property is the stability property that ensures players do not break apart from the grand coalition. The allocations in the core satisfy both of these properties. In general the core of CRI games can be empty. Below we provide an example where the core of the game associated with a CRI situation is empty.

Example 3. Consider the situation $\Gamma$ as follows. There are three players $N=\{1,2,3\}$, replenishing a single product $E_{1}=E_{2}=E_{3}=$ $\{a\}$. The replenishment costs from the intermediaries are separable and equal to 4 for all players, i.e., $r_{w}(\{i, a\})=4$ for all $i \in N$. The cost of replenishment from the manufacturer is as follows: $r_{m}(\{i, a\})=5$ for $i \in N, r_{m}(\{i, a\},\{j, a\})=5$ for $i, j \in N$ such that $i \neq j$, and $r_{m}(\{1, a\},\{2, a\},\{3, a\})=9$. It is straightforward to check that in this situation we have $c^{\Gamma}(S)=4$ if $|S|=1, c^{\Gamma}(S)=5$ if $|S|=2$, and $c^{\Gamma}(N)=9$. The game is symmetric so if the core is not empty, then the equal allocation of $9 / 3=3$ for every player must be in the core. However, every two player coalition can achieve the cost of 5 which is smaller than $3+3=6$. Thus the core of the game associated with $\Gamma$ is empty. $\triangle$

To provide insights about the nature of allocations in the core of CRI games we present an observation regarding the minimum amount of payments in separable situations.

Theorem 3. Let $\Gamma=\left(N, E, r_{w}, r_{m}\right) \in \Gamma$ be a situation with separable indirect replenishment costs. Let $X^{*}$ be an optimal replenishment policy for the grand coalition. For every allocation $\beta$ in the core of the associated game $\left(N, c^{\Gamma}\right)$ and every player $i \in N$ it holds that $\beta_{i} \geq r_{w}\left(\mathcal{X}_{i}^{\Gamma} \backslash X^{*}\right)$

Theorem 3 asserts that in every core allocation, each player has to pay at least its indirect replenishment cost for the products it obtains from the intermediaries in the grand coalition. Therefore, irrespective of the contribution of a player to the total cost savings, the indirect replenishment cost of no player would be subsi- dized in any core allocation. It is straightforward to observe that if a player replenishes a product directly from its manufacturer in an optimal replenishment policy, then in addition to its indirect replenishment cost, the player must pay a positive portion of its direct replenishment cost as well. Note that Theorem 3 does not require submodular situations and holds whenever a CRI game has a non-empty core.

Although the core of a cooperative game can be empty, the core of a concave game is always non-empty (Shapley, 1971). Our results in the previous section regarding the concavity of CRI games also guarantees the existence of allocations in the core.

Corollary 1. For every $\Gamma \in \Gamma^{s m}$ with separable indirect replenishment costs, the core of the associated cooperative CRI game $\left(\mathrm{N}, \mathrm{C}^{\Gamma}\right)$ is nonempty.

For the collaborative organization to be able to repeatedly carry out joint replenishments without the need of renegotiating the appropriate allocations, a formal scheme for allocating the costs in different situations should be in place. This requirement is formalized with the notion of allocation rule. An allocation rule is a function $\sigma$ which determines an allocation for every game in its domain of definition. The desirability of an allocation rule can be evaluated by the desirable properties of the allocations it generates. For example, an allocation rule is called efficient if it always generates efficient allocations. The allocation to player $i$ under allocation rule $\sigma$ is denoted with $\sigma_{i}$.

A well-known allocation rule in cooperative games literature is the Shapley value (Shapley, 1953). The Shapley value of a cost game $(N, c)$, i.e., $\Phi(N, c)$, for every $i \in N$ is calculated by the following formula:

$\Phi_{i}(N, c)=\sum_{S \subseteq N \backslash i} \frac{|S| !(n-|S|-1) !}{n !}[c(S \cup i)-c(S)]$.

The Shapley value divides the total cost of grand coalition according to the average contributions of players in all subsets that they are a member of. Because the Shapley value determines the players allocations based on their average contributions, it is often regarded as a fair allocation rule and hence it is deemed highly appropriate in many real-life situations-e.g. allocation of airport landing fees (Littlechild \& Owen, 1973), transmission costs (Tan \& Lie, 2002), pollution reduction costs (Petrosjan \& Zaccour, 2003), and logistics costs (Krajewska, Kopfer, Laporte, Ropke, \& Zaccour, 2007), among others.

In general the Shapley value of a game might not belong to its core. However, the core of a concave game always includes the Shapley value (Shapley, 1971). Therefore, in submodular CRI games with separable indirect replenishment costs players can always divide the costs among themselves in a stable and efficient way by implementing the Shapley value. Also, the Shapley value is a population monotonic allocation scheme (Sprumont, 1990) in concave games, which makes sure that inclusion of additional players to the group would never increase the cost allocated to any players. In the next section we demonstrate another appealing property of the Shapley value which holds in general CRI situations.

\section{Strategic participation in two-stage CRI games}

An implicit assumption made in the cooperative CRI game studied in previous section was that once a player decides to join the collaborative organization, it puts forward its entire product set so that their replenishment sources are decided by the collaborative organization in order to optimize the replenishment cost of the grand coalition. However, in reality the players' decisions with regard to their participation in collaborative replenishment activities is more nuanced. Most notably, the players can decide the 


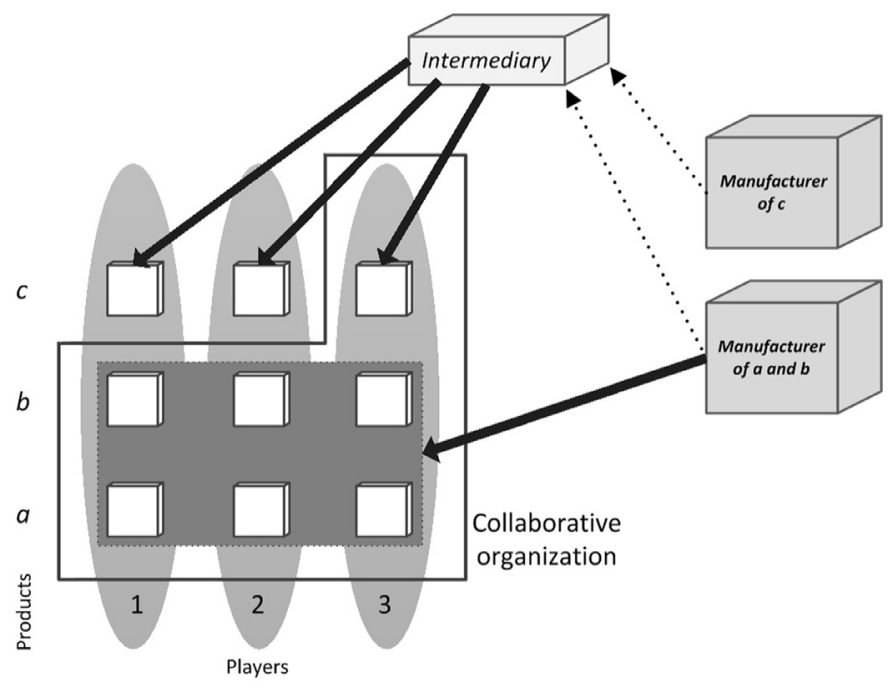

Fig. 2. Strategic participation in collaborative organization.

extent of participation in the collaborative organization in terms of the products whose replenishment policies are delegated to the collaborative organization. In this section, the players are allowed to partially collaborate. The participation decision with respect to each product is binary, i.e., each product is entirely replenished either within the collaborative organization or outside it. The question we investigate is the conditions under which centrally optimal outcomes would be achieved decentrally, i.e., strategic participation of the players would not negatively affect the total replenishment cost of the supply chain. Fig. 2 demonstrates an example where players 1 and 2 do not replenish product $c$ through the collaborative organization. In this case the collaborative organization replenishes product $c$ for player 3 from the intermediary and the rest of player-product pairs from the corresponding manufacturer.

A crucial input to the players' strategic decision making processes is the allocation rule that will be implemented in the collaborative organization to divide the joint costs. Hence, our analysis in this section enables us to comment on appropriate allocation rules in CRI situations. We construct a two-stage game comprising a non-cooperative stage followed by a subsequent cooperative stage. The sequence of events in our two-stage CRI game is as follows. First, the allocation rule for the collaborative organization is set and announced to the players. With this knowledge the players simultaneously make their decisions regarding the extent of their participation in the collaborative organization. That is, each player strategically chooses the products it would replenish via the collaborative organization. The cooperative CRI game played in the second stage is associated with the modified version of the original CRI situation which is induced by the players' participation strategies in the first stage. The total cost of the grand coalition in the induced CRI situation in the second stage will be distributed according to the pre-fixed allocation rule. Fig. 3 illustrates the sequence of events. We start by assuming that all information contained in the situation is known by all players.

Given a CRI situation $\Gamma=\left(N, E, r_{w}, r_{m}\right)$ and a player $i \in N$, let $L_{i} \subseteq E_{i}$ be the set of participating products of $i$. In this manner, $L_{i}$ is the participation strategy of player $i$. A vector of players' strategies $L=\left(L_{i}\right)_{i \in N}$ is referred to as a participation strategy profile. A participation strategy profile induces a CRI situation wherein only the participated products of the players are present. The modified situation induced by the participation strategy profile $L$ is denoted by $\Gamma[L]=\left(N, L, r_{w}, r_{m}\right)$. Subsequently, the game associated with the modified situation, to be played in the second stage, is $\left(N, c^{\Gamma[L]}\right)$.
Table 5

Situation $\Gamma$ in Example 4.

\begin{tabular}{lll}
\hline$X$ & $r_{w}(X)$ & $r_{m}(X)$ \\
\hline$\{(1, a)\}$ & 10 & 10 \\
$\{(2, a)\}$ & 10 & 10 \\
$\{(2, b)\}$ & 10 & 10 \\
$\{(1, a),(2, b)\}$ & 20 & 20 \\
$\{(1, a),(2, a)\}$ & 20 & 18 \\
$\{(2, a),(2, b)\}$ & 20 & 20 \\
$\{(1, a),(2, a),(2, b)\}$ & 30 & 25 \\
\hline
\end{tabular}

Table 6

Original and modified games in Example 4.

\begin{tabular}{lll}
\hline$S$ & $c^{\Gamma}(S)$ & $c^{\Gamma[L]}(S)$ \\
\hline$\{1\}$ & 10 & 10 \\
$\{2\}$ & 20 & 10 \\
$N$ & 25 & 18 \\
\hline
\end{tabular}

Example 4. Consider the CRI situation with $N=\{1,2\}, E_{1}=\{a\}$ and $E_{2}=\{a, b\}$. The cost components are shown in Table 5. The CRI game associated with this situation is shown in Table 6. Suppose that player 2 decides to participate only with his product $a$. The modified CRI game associated with the participation strategy $L=\left\{L_{1}=E_{1}, L_{2}=\{a\}\right\}$ is also shown in Table 6. In this case, player 2 will replenish product $b$ individually and outside of the cooperative organization. $\triangle$

Given an allocation rule $\sigma$ for CRI games, the two-stage participation game under allocation rule $\sigma$ is the triple $\left(N, \varnothing(E), z^{\Gamma, \sigma}\right)$ where $\wp(E)=\left(\wp\left(E_{i}\right)\right)_{i \in N}$ is the vector of individual participation choice sets-i.e., power sets of player-specific product sets-and $z^{\Gamma, \sigma}$ is the vector of player-specific cost functions with its $i$ th element, $i \in N$, defined such that for a participation strategy profile $L$ we have

$z_{i}^{\Gamma, \sigma}(L)=c^{\Gamma[E \backslash L]}(i)+\sigma_{i}\left(N, c^{\Gamma[L]}\right)$.

The player-specific cost function of player $i$ is comprised of the stand-alone replenishment cost of player $i$ for its withheld products and its allocation under $\sigma$ in the cooperative CRI game induced by $L$, i.e., the game associated with the modified CRI situation $\Gamma[L]$.

In two-stage CRI games, the individual decision making processes of the players are intertwined as the player-specific cost functions of players will be affected by the other players' choices of strategies as well. The rational players choose their individual participation strategies in anticipation of the other players' moves in order to minimize their player-specific cost functions. A particularly interesting outcome for the system is when the strategic choices of players coincide with the strategies that minimize the total replenishment costs of the entire system, i.e., when a centrally optimal participation strategy profile is selected individually by the players. In the latter case the supply chain would be coordinated. In the two-stage CRI game associated with $\Gamma$, the complete participation strategy profile $E$ minimizes the sum of player-specific cost functions so that the total equals $c^{\Gamma}(N)$. This observation follows from a technical result (Lemma 5) which we present in the supplement.

With the choice of complete participation strategy profiles there would be no loss of efficiency in the two-stage CRI games. However, despite the central optimality of complete participation strategy profiles in two-stage CRI games, players may choose other participation strategies if such strategies result in lower player-specific costs for them. An example of such behavior is reported by Granot and Sošić (2003) and Yan and Zhao (2015) in the context of transshipment games. A critical variable in this setting is the choice of allocation rule. 


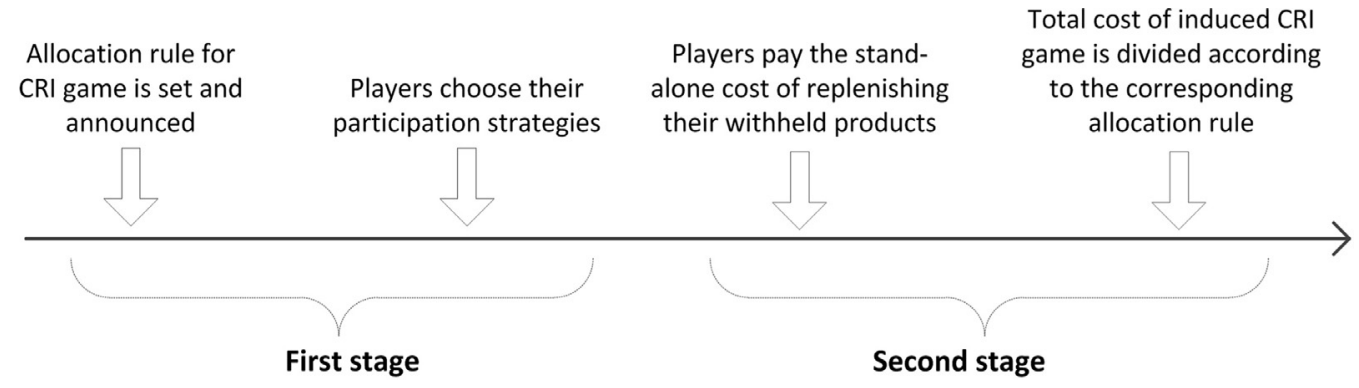

Fig. 3. Sequence of events in a two-stage CRI game.

Table 7

Two-stage CRI game in Example 5.

\begin{tabular}{llllll}
\hline & & $L_{2}$ & & & \\
\cline { 3 - 6 } & & $\emptyset$ & $\{a\}$ & $\{b\}$ & $\{a, b\}$ \\
\hline$L_{1}$ & $\emptyset$ & 10,20 & 10,20 & 10,20 & 10,20 \\
& $\{a\}$ & 10,20 & 9,19 & 10,20 & 5,20 \\
\hline
\end{tabular}

Example 5. Consider the CRI situation in Example 4. Suppose the chosen allocation rule assigns the costs proportional to the squared stand-alone costs of participating products of the players, that is given the strategy $L$ and for $i \in N$ we have $\sigma_{i}\left(N, c^{\Gamma[L]}\right)=$ $\left[c^{\Gamma[L]}(i)^{2} / \sum_{j \in N} c^{\Gamma[L]}(j)^{2}\right] c^{\Gamma[L]}(N)$. Table 7 shows the two-stage CRI game associated with this situation. Each cell in the table gives the player-specific costs of both players under the corresponding participation strategy. Observe that the strategy profile $L=$ $\left(L_{1}=\{a\}, L_{2}=\{a\}\right)$ is a Nash equilibrium-as well as the weaklydominant strategy profile. However, this strategy profile does not result in centrally optimal total costs as the allocation rule chosen does not induce complete participation. $\Delta$

The following definition captures the formal relation between the choice of allocation rules and the players' participation strategies in two-stage CRI games.

Definition 3. Let $\Gamma=\left(N, E, r_{w}, r_{m}\right) \in \Gamma$ and suppose allocation rule $\sigma$ is given. We say $\sigma$ implements the participation strategy profile $L \in \wp_{0}(E)$ in Nash equilibrium (respectively, weakly dominant strategies) in the two-stage CRI game associated with $\Gamma$ if $L$ is a Nash equilibrium (respectively, a weakly dominant strategy profile) in that game.

Definition 3 introduces two types of implementations. From Section 3, Nash equilibrium implementation requires that for every $i \in N$ and every $L_{i}^{\prime} \in \wp^{\circ}\left(E_{i}\right)$ it holds that $z_{i}^{\Gamma, \sigma}(L) \leq z_{i}^{\Gamma, \sigma}\left(L_{i}^{\prime}, L_{-i}\right)$. Also, the second type of implementation, i.e. weakly dominant strategies, implies that for every $i \in N$ and every $L^{\prime} \in \wp(E)$ it holds that $z_{i}^{\Gamma, \sigma}\left(L_{i}, L_{-i}^{\prime}\right) \leq z_{i}^{\Gamma, \sigma}\left(L^{\prime}\right)$. Remember from Section 3 that every weakly dominant strategy profile is also a Nash equilibrium. Thus, if an allocation rule could implement a participation strategy profile in weakly dominant strategies it can also implement that strategy in Nash equilibrium. The reverse, however, may not hold necessarily. It has been argued that implementation in (weakly) dominant strategies is the most demanding form of implementation (Maskin \& Sjöström, 2002). In the next step we present the main result of this section regarding the ability of the Shapley value to implement centrally optimal participation strategy profiles in twostage CRI games.

Theorem 4. The Shapley value implements the complete participation strategy profile in weakly dominant strategies in every two-stage CRI game.
According to Theorem 4, if the Shapley value is set as the allocation rule, no player can obtain any benefit by withholding some of its products from the collaborative organization. The power of the Shapley value in enforcing the centrally optimal strategies in CRI situations becomes clearer once we realize that the complete participation strategy is a feasible choice for every player in every CRI situation. The next observation follows immediately.

Corollary 2. Let $i \in N$ be a player. With the Shapley value as the allocation rule, the complete participation strategy $E_{i}$ is the best strategy for player $i$ in every two-stage CRI game irrespective of the strategies of all other players.

Corollary 2 has important consequences in terms of the information available to every player and its effect on the choice of centrally optimal participation strategies. Since complete participation strategies are always best choices of strategies at the individual level under the Shapley value, the players do not need to know the specific details of the situation in order to realize that announcing their complete player-specific product sets to the collaborative organization is their best options. We conclude that the Shapley value can lead to the coordination of the decentralized system under study even in settings with asymmetric information.

\section{Source-specific replenishment organizations}

The collaborative organizations in previous sections make decisions on the replenishment sources of the products that are requested by the players. We study an alternative structure for collaborative organizations in this section which might be easier to manage. That is, we consider two types of source-specific replenishment organizations such that one purchases every requested product from the intermediaries and the other purchases solely from the manufacturers. Thus, the collaborative organizations in this section do not make strategic sourcing decisions. Drawing upon the logic of two-stage games elaborated upon previously, the purpose of this section is to answer the following question: can buyers be motivated, through the choice of right allocation rules, to participate in the two collaborative organizations such that centrally optimal replenishment policies be attained? Thus, we examine if sourcing decisions can be efficiently decentralized. Fig. 4 shows an example of this structure. Player 1 replenishes product $b$ as well as product $c$ together with players 2 and 3 from the collaborative organization that buys everything from the intermediary. The players replenish the rest of their products via the collaborative organization which buys everything from the corresponding manufacturers. Comparing this figure with Fig. 1 reveals that any replenishment strategy prescribed by the former kind of collaborative organization can be obtained via a corresponding participation strategy for the players in source-specific replenishment organizations.

To carry out the analysis, we construct two alternative source-specific cooperative games. Given the CRI situation $\Gamma=$ 


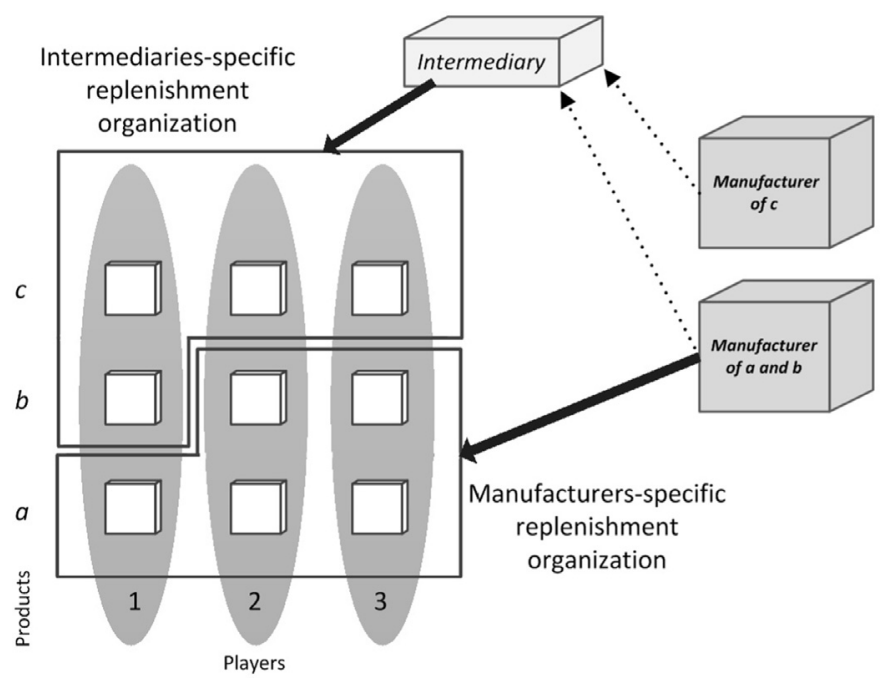

Fig. 4. Participation in source-specific replenishment organizations.

$\left(N, E, r_{w}, r_{m}\right)$, define the direct CRI game $\left(N, c_{m}^{\Gamma}\right)$ and the indirect CRI game $\left(N, c_{w}^{\Gamma}\right)$ where for every $S \subseteq N$ :

$c_{m}^{\Gamma}(S)=r_{m}\left(\mathcal{X}_{S}^{\Gamma}\right), \quad$ and $\quad c_{w}^{\Gamma}(S)=r_{w}\left(\mathcal{X}_{S}^{\Gamma}\right)$.

The cost to every coalition in the direct (indirect) CRI game is the direct (indirect) replenishment cost of all products of every player. In this manner, source-specific CRI games disregard the alternative option for replenishments. Subsequently, we define alternative two-stage games associated with CRI situations in the same spirit as in the previous section. In the first stage of this game, each player decides the products it would replenish in either of the source-specific replenishment organizations knowing the allocation rules for the corresponding games. In the second stage, the source-specific cooperative games induced by the chosen strategies is played and the costs will be divided according to the pre-fixed allocation rules. We refer to these two-stage games as the sourcespecific two-stage CRI games. Fig. 5 depicts the sequence of events in these games.

The source-specific two-stage CRI game associated with situation $\Gamma=\left(N, E, r_{w}, r_{m}\right)$ under allocation rules $\sigma$ and $\tilde{\sigma}$, corresponding to indirect and direct replenishment games respectively, is the triple $\left(N, \wp(E), \tilde{z}^{\Gamma, \sigma, \tilde{\sigma}}\right)$ where $\wp(E)=\left(\wp\left(E_{i}\right)\right)_{i \in N}$ is the vector of individual participation choice sets, and $\tilde{z}^{\Gamma, \sigma, \tilde{\sigma}}$ is the vector of alternative player-specific cost functions with its $i$ 'th element, $i \in N$, defined such that for a strategy profile $L \in \prod_{i \in N \wp(}\left(E_{i}\right)$, which represents the products that each player replenishes via direct collaborative organization, we have

$w_{i}^{\Gamma, \sigma, \tilde{\sigma}}(L)=\sigma_{i}\left(N, c_{m}^{\Gamma[L]}\right)+\tilde{\sigma}_{i}\left(N, c_{w}^{\Gamma[E \backslash L]}\right)$.

Thus the cost to a player in the above games is the sum of allocations in corresponding direct and indirect replenishment games associated with the participation strategy of the players.

From the formulation in (6) it must be evident that there is a bijection between the set of participation strategies for a sourcespecific two-stage CRI game and the replenishment policies in the original situation. Drawing upon the latter fact, the next observation, which we provide without proof, highlights a centrally optimal participation strategy profile for a source-specific two-stage CRI game that minimizes the sum of player-specific cost functions of the players so that the total boils down to the minimum total replenishment cost of the corresponding centralized system. In the source-specific two-stage CRI game associated with $\Gamma$, the participation strategy profile $L^{*}=X^{*}$ minimizes the sum of playerspecific cost functions so that the total equals $c^{\Gamma}(N)$. Thus, if play-
Table 8

Situation $\Gamma$ in Example 6.

\begin{tabular}{lll}
\hline$X$ & $r_{w}(X)$ & $r_{m}(X)$ \\
\hline$\{(1, a)\}$ & 9 & 10 \\
$\{(2, a)\}$ & 9 & 10 \\
$\{(1, b)\}$ & 9 & 10 \\
$\{(1, a),(1, b)\}$ & 16 & 20 \\
$\{(1, a),(2, a)\}$ & 18 & 15 \\
$\{(2, a),(1, b)\}$ & 18 & 20 \\
$\{(1, a),(2, a),(1, b)\}$ & 25 & 25 \\
\hline
\end{tabular}

Table 9

Situation $\hat{\Gamma}$ in Example 3.

\begin{tabular}{lll}
\hline$X$ & $r_{w}(X)$ & $r_{m}(X)$ \\
\hline$\{(1, a)\}$ & 9 & 10 \\
$\{(2, a)\}$ & 9 & 10 \\
$\{(2, b)\}$ & 9 & 10 \\
$\{(2, a),(2, b)\}$ & 16 & 20 \\
$\{(1, a),(2, a)\}$ & 18 & 15 \\
$\{(1, a),(2, b)\}$ & 18 & 20 \\
$\{(1, a),(1, b),(2, b)\}$ & 25 & 25 \\
\hline
\end{tabular}

ers choose the right participation strategies, then there would be no efficiency lost in the setting with source-specific replenishment organizations. In fact, minimum total replenishment cost of the centralized system can be achieved if each player puts forward the same set of products to direct collaborative replenishment organization that it should have replenished from manufacturers in an optimal replenishment policy for the corresponding CRI situation. Modifying the notion of implementation in Definition 3 for sourcespecific two-stage CRI games, next we investigate the existence of allocation rules that could implement centrally optimal participation strategy profiles in these games. As we show in the example below, such allocation rules do not exists even if we require implementation in the weaker form, i.e., in Nash equilibrium.

Example 6. Consider the CRI situation $\Gamma$ with $N=\{1,2\}, E_{1}=$ $\{a, b\}$ and $E_{2}=\{a\}$. The cost components for different policies are given in Table 8. In the CRI game associated with this situation we have $c^{\Gamma}(\{1\})=16, c^{\Gamma}(\{2\})=9$, and $c^{\Gamma}(N)=9+15=24$. Observe that the only centrally optimal participation strategy profile in the source-specific two-stage game associated with $\Gamma$ is $L^{*}=\left(L_{1}^{*}=\{a\}, L_{2}^{*}=E_{2}\right)$. That is, player 1 should replenish product $b$ indirectly. The modified situation in the direct replenishment game associated with the latter participation strategy profile is $\Gamma\left[L^{*}\right]=\left(N,(\{a\},\{a\}), r_{w}, r_{m}\right)$. The modified situation in the indirect replenishment game associated with the latter participation strategy profile is $\Gamma\left[E \backslash L^{*}\right]=\left(N,(\{b\},\{\}), r_{w}, r_{m}\right)$. Accordingly, in the indirect CRI game associated with modified situation $\Gamma\left[E \backslash L^{*}\right]$ we have $c_{w}^{\Gamma\left[E \backslash L^{*}\right]}(\{1\})=9, c_{w}^{\Gamma\left[E \backslash L^{*}\right]}(\{2\})=0$, and $c_{w}^{\Gamma\left[E \backslash L^{*}\right]}(N)=9$. In the modified direct $C R I$ game associated with situation $\Gamma\left[L^{*}\right]$ we have $c_{m}^{\Gamma\left[L^{*}\right]}(\{1\})=c_{m}^{\left.\Gamma L^{*}\right]}(\{2\})=10$, and $c_{m}^{\Gamma\left[L^{*}\right]}(N)=15$.

Next, consider the situation $\hat{\Gamma}$ with $N=\{1,2\}, E_{1}=\{a\}$ and $E_{2}=\{a, b\}$ and cost components that are given in Table 9. It can be seen that $c^{\hat{\Gamma}}(\{1\})=9, c^{\hat{\Gamma}}(\{2\})=16, c^{\hat{\Gamma}}(N)=9+15=24$. The unique optimal participation strategy profile in the sourcespecific two-stage game associated with $\hat{\Gamma}$ is $\hat{L}^{*}=\left(\hat{L}_{1}^{*}=E_{1}, \hat{L}_{2}^{*}=\right.$ $\{a\})$. The modified situation in the direct replenishment game associated with the latter participation strategy profile is $\hat{\Gamma}\left[\hat{L}^{*}\right]=$ $\left(N,(\{a\},\{a\}), r_{w}, r_{m}\right)$. The modified situation in the indirect replenishment game associated with the latter participation strategy profile is $\hat{\Gamma}\left[E \backslash \hat{L}^{*}\right]=\left(N,(\{\},\{b\}), r_{w}, r_{m}\right)$. In the indirect CRI game associated with modified situation $\hat{\Gamma}\left[E \backslash L^{*}\right]$ we have $c_{w}^{\hat{\Gamma}\left[E \backslash \hat{L}^{*}\right]}(\{1\})=$ $0, c_{w}^{\hat{\Gamma}\left[E \backslash \hat{L}^{*}\right]}(\{2\})=9$, and $c_{w}^{\hat{\Gamma}\left[E \backslash \hat{L}^{*}\right]}(N)=9$. In the modified direct 


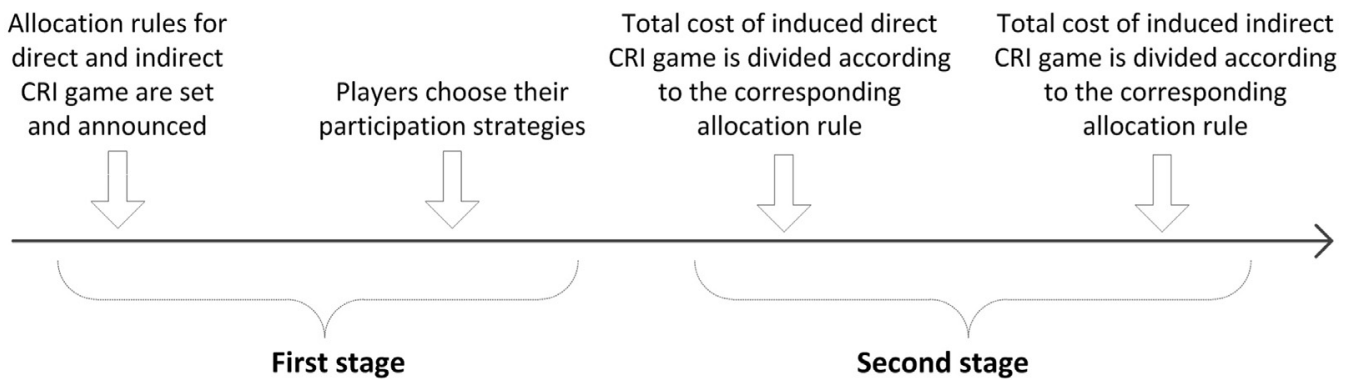

Fig. 5. Sequence of events in a source-specific two-stage CRI game.

CRI game associated with situation $\hat{\Gamma}\left[\hat{L}^{*}\right]$ we have $c_{m}^{\hat{\Gamma}\left[\hat{L}^{*}\right]}(\{1\})=$ $c_{m}^{\hat{\Gamma}\left[\hat{L}^{*}\right]}(\{2\})=10$, and $c_{m}^{\hat{\Gamma}\left[\hat{L}^{*}\right]}(N)=15$.

Any efficient and individually rational allocation rule $\sigma$ for the indirect replenishment games obtains $\tilde{\sigma}\left(N, c_{w}^{\Gamma\left[E \backslash L^{*}\right]}\right)=(9,0)$ and $\tilde{\sigma}\left(N, c_{w}^{\hat{\Gamma}\left[E \backslash \hat{L}^{*}\right]}\right)=(0,9)$. For the direct replenishment game, suppose that an efficient and individually rational allocation rule $\sigma$ is chosen that divides the costs between the players in such a way that $\sigma_{1}\left(N, c_{m}^{\Gamma\left[L^{*}\right]}\right) \geq \sigma_{2}\left(N, c_{m}^{\Gamma\left[L^{*}\right]}\right)$. Consider the situation $\Gamma$. With any efficient and individually rational allocation rule $\tilde{\sigma}$ for the indirect replenishment game and the allocation rule $\sigma$ described above, it would be the case that

$w_{1}^{\Gamma, \sigma, \tilde{\sigma}}\left(L^{*}\right)=\sigma_{1}\left(N, c_{w}^{\Gamma\left[E \backslash L^{*}\right]}\right)+\tilde{\sigma}_{1}\left(N, c_{m}^{\Gamma\left[L^{*}\right]}\right) \geq 7.5+9=16.5$.

In this situation, if player 1 deviates from choosing $L_{1}^{*}$ and instead chooses $L_{1}=\{\}$, while player 2 chooses $L_{2}^{*}$, allocation rule $\tilde{\sigma}$ obligates player 1 to pay 16 and allocation rule $\sigma$ assigns zero payments to player 1 (since its stand-alone cost in the corresponding direct replenishment game is zero). Thus, player 1 would get $w_{1}^{\Gamma, \sigma, \tilde{\sigma}}\left(L_{1}, L_{2}^{*}\right)=16<w_{1}^{\Gamma, \sigma, \tilde{\sigma}}\left(L^{*}\right)$. Therefore the choice of $\sigma$ as above results in optimal participation strategy profile not being a Nash equilibrium in this situation.

To remedy this, suppose a different allocation rule $\sigma^{\prime}$ is chosen such that $\sigma_{1}^{\prime}\left(N, c_{m}^{\left[L^{*}\right]}\right)<\sigma_{2}^{\prime}\left(N, c_{m}^{\Gamma\left[L^{*}\right]}\right)$. However, once we apply these allocation rules to the original situation $\hat{\Gamma}$, a similar argument as above shows that a direct allocation rule that gives player 2 a higher allocation than player 1 is unable to implement the corresponding centrally optimal participation strategy profile in Nash equilibrium. We conclude that there exists no allocation rules that could implement the optimal participation strategy profiles in Nash equilibrium in source-specific two-stage CRI games associated with situations $\Gamma$ and $\hat{\Gamma}$ simultaneously. $\triangle$

Thus, we can state the following final result.

Theorem 5. There exists no efficient and individually rational allocation rules for indirect and direct CRI games that could implement the centrally optimal participation strategy profiles in every sourcespecific two-stage CRI game.

The result of the last theorem is that the strategic participation of players in source-specific replenishment organizations can damage optimal supply chain efficiency. Moreover, the fact that indirect replenishment costs in Example 6 are separable means that even when collaborative replenishment from intermediaries are not beneficial, having a collaborative organization that solely deals with purchases from manufacturers can attain sub-optimal supply chain performance. Hence, to obtain the system wide optimal performance, it is crucial that a single collaborative replenishment organization considers the players' replenishment options both from the intermediaries and the manufacturers.

\section{Final remarks}

In this paper, we investigated potential opportunities for direct and indirect replenishments for collaborating downstream buyers in supply chains with alternative sources of supply. In a typical situation with the intermediaries offering low order costs, possibility to bundle multiple products in one order, yet higher unit costs than manufacturers, the incentives for replenishing from different sources are conflicting. The main insight obtained from our study is that although collaboration is always fruitful, under certain conditions the buyers' incentives can be aligned with a choice of right allocation rules so that the corresponding collaborative organization is both stable and welcoming to new members. However, collaborative organization should take control of both indirect and direct replenishment of the buyers to guarantee optimal supply chain performance. For example, the collaborative organization might require buyers to obtain low-demand products from the intermediaries and high-demand products from the manufacturers. In this regard, collaboration increases the supply chain efficiency by eliminating double marginalization and excessive inventories.

The conditions that guarantee the stability of collaborative organizations in our setting are sub-modularity and separability of situations. As we prove, sub-modularity of both direct and indirect cost components are a sufficient condition for sub-modularity of the situation. Although there are many examples of sub-modular cost components in the literature, it must be noted that non-submodular cost components exist as well. The latter happens for example when additional logistical constraints such as truck capacities and product shortages are taken into consideration (see for example Engevall, Göthe-Lundgren, \& Värbrand, 2004).

We showed that the Shapley value possesses several desirable properties for being the allocation rule of choice in CRI situations. Apart from its appealing properties in concave games, the Shapley value implements complete participation strategy profiles in all CRI situations in such a way that for every player, delegating the replenishment decisions of all products to the collaborative organization is the best strategy, even if no information about the other players is available. As we work under the assumption of complete information regarding the cost components, the input for calculating the Shapley value would be readily available as soon as the players enter the collaborative organization by revealing their product sets. We further showed that even if collaborative replenishments from intermediaries do not provide additional benefits, the collaborative organization that focuses on direct replenishments from manufacturers but allows buyers to partially participate may never achieve efficient outcomes.

There are many other perspectives to consider when horizontal collaboration in supply chains are carried out in the presence of intermediaries. Joint replenishment activities are likely to affect the pricing schemes of manufacturers, intermediaries, and downstream buyers. So an important direction for future research is to study the dynamics stemming from price competitions among supply chain entities. This would be in line with the work of James 
and Dana (2012) who study the impact of collaborative purchasing organizations on price competition among the suppliers. It is worth mentioning that although collaborative purchasing results in lower purchasing prices for the downstream players, competition in price-setting may leave them worse off-an instance of this situation discussed by Chen and Roma (2011). Another possible extension of our work is to address the additional costs faced by the organizations of collaborating buyers. It has been observed in the literature, e.g., in Hezarkhani and Kubiak (2013), that increasing collaboration costs can be a threat to the stability in supply chains. Hence, it is important to understand to what extent collaborative organizations can afford the increasing costs of required communication, negotiations, and infrastructure. We leave these for future research.

\section{Acknowledgments}

The authors are grateful to the associate editor and three anonymous referees whose suggestions improved the paper.

\section{Supplementary material}

Supplementary material associated with this article can be found, in the online version, at 10.1016/j.ejor.2017.09.033.

\section{References}

Automotive Aftermarket Suppliers Association, AASA (2012). Aftermarket supplier barometer. URL http://www.aftermarketsuppliers.org/.

Anily, S., \& Haviv, M. (2007). The cost allocation problem for the first order interaction joint replenishment model. Operations Research, 55(2), 292-302.

Anupindi, R., Bassok, Y., \& Zemel, E. (2001). A general framework for the study of decentralized distribution systems. Manufacturing \& Service Operations Management, 3(4), 349-368.

Appel, A., Franz, M., \& Hassler, M. (2014). Intermediaries in agro-food networks in turkey: How middlemen respond to transforming food market structures. DIE ERDE-Journal of the Geographical Society of Berlin, 145(3), 148-157.

Brandenburger, A., \& Stuart, H. (2007). Biform games. Management Science, 53(4), 537-549.

Bylka, S. (2011). Non-cooperative strategies for production and shipment lot sizing in one vendor-multi-buyer system. International Journal of Production Economics, 131(1), 372-382.

Chen, R. R., \& Roma, P. (2011). Group buying of competing retailers. Production and Operations Management, 20(2), 181-197.

DINALOG (2017). IZI-motive project. URL https://www.dinalog.nl/en/project/ izi-motive/.

Dror, M., \& Hartman, B. C. (2007). Shipment consolidation: Who pays for it and how much? Management Science, 53(1), 78-87.

Dror, M., \& Hartman, B. C. (2011). Survey of cooperative inventory games and extensions. Journal of the Operational Research Society, 62(4), 565-580.

London Economics (2006). Developments in car retailing and after-sales markets under regulation No. 1400/2002: vol. 1. European Commission.

Engevall, S., Göthe-Lundgren, M., \& Värbrand, P. (2004). The heterogeneous vehicle-routing game. Transportation Science, 38(1), 71-85.

Fiestras-Janeiro, G. M., García-Jurado, I., Meca, A., \& Mosquera, M. A. (2011). Cooperative game theory and inventory management. European Journal of Operational Research, 210(3), 459-466.

Gillies, D. B. (1959). Solutions to general non-zero-sum games. Contributions to the Theory of Games, 4, 47-85.

Granot, D., \& Sošić, G. (2003). A three-stage model for a decentralized distribution system of retailers. Operations Research, 51(5), 771-784.

Grötschel, M., Lovász, L., \& Schrijver, A. (1988). Geometric algorithms and combinatorial optimization. Berlin: Springer.

Guardiola, L. A., Meca, A., \& Puerto, J. (2008). Production-inventory games and PMAS-games: Characterizations of the owen point. Mathematical Social Sciences, 56(1), 96-108.

Guardiola, L. A., Meca, A., \& Puerto, J. (2009). Production-inventory games: A new class of totally balanced combinatorial optimization games. Games and Economic Behavior, 65(1), 205-219.

Hartman, B. C., Dror, M., \& Shaked, M. (2000). Cores of inventory centralization games. Games and Economic Behavior, 31(1), 26-49.

Heuvel, W. V. d., Borm, P., \& Hamers, H. (2007). Economic lot-sizing games. European Journal of Operational Research, 176(2), 1117-1130.

Hezarkhani, B., \& Kubiak, W. (2013). Transshipment games with identical newsvendors and cooperation costs. Mathematical Methods of Operations Research, 78(3), 315-339.

Hu, Q., Schwarz, L. B., \& Uhan, N. A. (2012). The impact of group purchasing organizations on healthcare-product supply chains. Manufacturing \& Service Operations Management, 14(1), 7-23.
Jackson, P., Maxwell, W., \& Muckstadt, J. (1985). The joint replenishment problem with a powers-of-two restriction. IIE Transactions, 17(1), 25-32.

James, D., \& Dana, Jr. (2012). Buyer groups as strategic commitments. Games and Economic Behavior, 74(2), 470-485.

Karsten, F., \& Basten, R. (2014). Pooling of spare parts between multiple users: How to share the benefits? European Journal of Operational Research, 233(1), 94-104.

Karsten, F., Slikker, M., \& van Houtum, G. J. (2012). Inventory pooling games for expensive, low-demand spare parts. Naval Research Logistics, 59(5), 311-324.

Kemahlioglu-Ziya, E., \& Bartholdi, J. III. (2011). Centralizing inventory in supply chains by using shapley value to allocate the profits. Manufacturing \& Service Operations Management, 13(2), 146-162.

Körpeoğlu, E., Şen, A., \& Güler, K. (2012). A private contributions game for joint replenishment. Mathematical Methods of Operations Research, 75(1), 67-82.

Körpeoğlu, E., Sen, A., \& Güler, K. (2013). Non-cooperative joint replenishment under asymmetric information. European Journal of Operational Research, 227(3), 434-443.

Krajewska, M. A., Kopfer, H., Laporte, G., Ropke, S., \& Zaccour, G. (2007). Horizontal cooperation among freight carriers: Request allocation and profit sharing. Journal of Operational Research Society, 59(11), 1483-1491.

Littlechild, S. C., \& Owen, G. (1973). A simple expression for the shapley value in a special case. Management Science, 20(3), 370-372.

Maskin, E., \& Sjöström, T. (2002). Implementation theory: Vol. 1. Handbook of social choice and welfare (pp. 237-288). Elsevier.

Meca, A., García-Jurado, I., \& Borm, P. (2003). Cooperation and competition in inventory games. Mathematical Methods of Operations Research, 57(3), 481-493.

Meca, A., \& Sošić, Gr. (2014). Benefactors and beneficiaries: The effects of giving and receiving on cost-coalitional problems. Production and Operations Management, 23(9), 1549-1560.

Meca, A., \& Sošíc, G. (2016). On supremum-norm cost games. Operations Research Letters, 44(1), 54-58.

Meca, A., Timmer, J., Garcia-Jurado, I. \& Borm, P. (2004). Inventory games. European Journal of Operational Research, 156(1), 127-139.

Montrucchio, L., Norde, H., Özen, U., Scarsini, M., \& Slikker, M. (2012). Cooperative newsvendor games: A review. In Handbook of newsvendor problems (pp. 137-162). Springer.

Moss, D. L. (2012). Healthcare intermediaries: Competition and healthcare policy at loggerheads? Technical report, American Antitrust Institute Working Paper.

Nagarajan, M., Sošic, G., \& Zhang, H. (2010). Stable group purchasing organizations. Vancouver: University of British Columbia Working paper.

Nash, J. F. (1950). Equilibrium points in n-person games. Proceedings of the national academy of sciences, 36(1), 48-49.

Owen, G. (1975). On the core of linear production games. Mathematical Programming, 9(1), 358-370.

Özen, U., Fransoo, J., Norde, H., \& Slikker, M. (2008). Cooperation between multiple newsvendors with warehouses. Manufacturing \& Service Operations Management, 10(2), 311-324.

Özen, U., Norde, H., \& Slikker, M. (2011). On the convexity of newsvendor games. International Journal of Production Economics, 133(1), 35-42.

Petrosjan, L., \& Zaccour, G. (2003). Time-consistent shapley value allocation of pollution cost reduction. Journal of Economic Dynamics and Control, 27(3), 381-398.

Purvis, L., Naim, M., \& Towill, D. (2013). Intermediation in agile global fashion supply chains. International Journal of Engineering, Science and Technology, 5(2), $38-48$.

Schaarsberg, M. G., Borm, P., Hamers, H., \& Reijnierse, H. (2013). Game theoretic analysis of maximum cooperative purchasing situations. Naval Research Logistics, 60(8), 607-624.

Schotanus, F., Telgen, J., \& de Boer, L. (2008). Unfair allocation of gains under the equal price allocation method in purchasing groups. European Journal of Operational Research, 187(1), 162-176.

Shapley, L. (1953). Contributions to the theory of games: Vol. II. A value for n-person games (pp. 307-317). Princeton University Press.

Shapley, L. (1971). Cores of convex games. International Journal of Game Theory, 1(1), $11-26$.

Slikker, M., Fransoo, J., \& Wouters, M. (2005). Cooperation between multiple news-vendors with transshipments. European Journal of Operational Research, 167(2), 370-380.

Sprumont, Y. (1990). Population monotonic allocation schemes for cooperative games with transferable utility. Games and Economic Behavior, 2(4), 378-394.

Spulber, D. F. (1996). Market microstructure and intermediation. The Journal of Economic Perspectives, 10(3), 135-152

Stuart, H. W., Jr. (2005). Biform analysis of inventory competition. Manufacturing \& Service Operations Management, 7(4), 347-359.

Tan, X., \& Lie, T. T. (2002). Application of the shapley value on transmission cost allocation in the competitive power market environment. IEE Proceedings-Generation, Transmission and Distribution, 149(1), 15-20.

Timmer, J., Chessa, M., \& Boucherie, R. J. (2013). Cooperation and game-theoretic cost allocation in stochastic inventory models with continuous review. European Journal of Operational Research, 231(3), 567-576.

Wu, S. D. (2004). Supply chain intermediation: A bargaining theoretic framework. Handbook of quantitative supply chain analysis: Modeling in the e-business era (pp. 67-115). Kluwer.

Yan, X., \& Zhao, H. (2015). Inventory sharing and coordination among $n$ independent retailers. European Journal of Operational Research, 243(2), 576-587.

Zhang, J. (2009). Cost allocation for joint replenishment models. Operations Research, $57(1), 146-156$ 